Fukushima J. Med. Sci.,

Vol. 58, No. 1, 2012

[Original Article]

\title{
THE ENDOCRINOLOGICAL RESPONSES OF VENO-VENOUS EXTRACORPOREAL MEMBRANE OXYGENATION ON HYPOXIC FETAL LAMBS
}

\author{
YASUHISA NOMURA, KATSUHIKO KATO, KEIYA FUJIMORI, \\ TOMOHIRO SHIROTO, TOMOHIKO ISHIDA and AKIRA SATO \\ Department of Obstetrics and Gynecology, School of Medicine, Fukushima Medical University
}

(Received September 16, 2011, accepted December 5, 2011)

\begin{abstract}
:
Objective: The purpose of this study was to observe endocrinological responses of venoarterial and veno-venous extracorporeal membrane oxygenation (V-A and V-V ECMO) to support fetal oxygenation in utero.

Methods : An ECMO system with a centrifugal pump was applied to six chronically instrumented fetal lambs, at 126-134 days of gestation. Blood was obtained through a double-lumen catheter inserted into the right atrium. After oxygenation, the blood was returned through a single-lumen catheter into either the carotid artery (veno-arterial ; V-A ECMO) or the right atrium (V-V ECMO). After fetal hypoxia had been experimentally produced, V-A ECMO or V-V ECMO was instituted to maintain fetal oxygenation. We compared fetal blood gases and concentrations of atrial natriuretic peptide (ANP), epinephrine and norepinephrine with both routes of ECMO.

Results : Fetal carotid artery $\mathrm{pH}$ did not change during hypoxemia, but decreased after instituting V-A ECMO and V-V ECMO. After instituting V-A ECMO or V-V ECMO for 30 min, oxygen partial pressure (pO2) in the fetal cranial carotid artery recovered from the hypoxic level. The ANP concentration in V-V ECMO was significantly lower than that in V-A ECMO. Fetal serum epinephrine and norepinephrine concentrations significantly increased in association with hypoxic stimulation. There was a further increase in fetal serum epinephrine concentration after instituting V-A ECMO. No significant difference in concentration was found after instituting V-V ECMO from that of after the institution of V-A ECMO.

Conclusions : This study suggested that V-V ECMO may possibly be less invasive than V-A ECMO for fetal heart, because ANP, a cardiac distress index, was lower in V-V ECMO than in V-A ECMO.
\end{abstract}

Key words : Extracorporeal membrane oxygenation (ECMO), hypoxia, fetus, sheep, atrial natriuretic peptide (ANP)

\section{INTRODUCTION}

Extracorporeal membrane oxygenation (ECMO) was first used in the treatment of newborn babies in $1976^{1)}$. Since then, ECMO has rapidly been developed for the management of respiration/circulation assistance in severe meconium aspiration syndrome and diaphragmatic hernia in neonatal medicine ${ }^{2)}$. However, few studies have been conducted on intrauterine ECMO systems for fetal-placental circulation in fetuses. There have been two reports by Murata and coworkers where they prepared chronic fetal sheep experiment models in which the mothers were kept under hypoxic conditions to institute

野村泰久, 加藤克彦, 藤森敬也, 白戸智洋, 石田友彦, 佐藤 章

Corresponding author: Yasuhisa Nomura MD E-mail address : nomura@fmu.ac.jp

https://www.jstage.jst.go.jp/browse/fms http://www.fmu.ac.jp/home/lib/F-igaku/ 
veno-arterial (V-A) ECMO. Blood was obtained from the fetal right atrium and oxygenated blood was returned to the caudal carotid artery, contributing to the improvement in fetal oxygen concentrations $^{3,4)}$. Recently, a less invasive method of venovenous $(\mathrm{V}-\mathrm{V}) \mathrm{ECMO}$, which is performed with one double lumen catheter placed into the right atrium via the right jugular vein to obtain and return blood, has been applied to newborn babies in clinical settings ${ }^{5,6)}$. We believe that V-V ECMO is a less traumatic system than V-A ECMO because the former uses a single double lumen catheter. V-V ECMO is reportedly a useful treatment when applied to fetuses as it provides sufficient oxygenation of the myocardia and physiologic hemodynamics ${ }^{7}$. It has been indicated that fetal-placental circulation involves various vasoconstrictors, vasodilators, and stress hormones. Moreover, fetal atrial natriuretic peptide (ANP), epinephrine and norepinephrine have reportedly increased in fetal hypoxic conditions $^{8,9)}$. We therefore examined the impact of $\mathrm{V}-\mathrm{V}$ ECMO on fetal endocrinal kinetics, fetal arterial blood gas, fetal heart rate, and fetal blood pressure in fetal-placental circulation.

\section{MATERIAL AND METHODS}

\section{Animal preparation}

The present study was carried out under the control of the Animal Research Committee in accordance with The Guidelines on Animal Experiments in Fukushima Medical University. Studies were carried out at Fukushima Medical University, Fukushima, Japan, using six pregnant Suffolk sheep of known gestational age. The sheep were maintained in an air-conditioned room and given free access to food and water. Surgery was performed from 125 to 133 days gestation (full term $=145$ days) after a $24 \mathrm{~h}$ maternal fast. Anesthesia was induced with atropine sulfate (1 mg per body) and xylazine $(0.2 \mathrm{mg} / \mathrm{kg})$ intramuscularly and was maintained with ketamine $(3 \mathrm{mg} / \mathrm{kg})$ intravenously at 30 min intervals. Using aseptic techniques, a midline skin incision was made. The fetal head was delivered through a hysterotomy incision and covered with a surgical glove filled with warm saline. A pair of stainless steel electrodes attached to polyvinyl chloride-coated stainless steel wires (Cooner, Chatsworth, CA, USA), were placed on the fetal trunk for the fetal electrocardiogram (FECG). The fetal heart rate (FHR) was obtained from the FECG. A 12-Fr Teflon double-lumen catheter
(Bard Access System Ltd, Salt Lake City, UT, USA) was inserted caudally into the right jugular vein through an incision in the fetal neck until the tip of the catheter entered the right atrium under ultrasound guidance. The left carotid artery was isolated and a 9-Fr Teflon single-lumen catheter (Bard Access System Ltd) was threaded caudally. Polyvinyl chloride catheters $(1.7 \mathrm{~mm}$ OD and 0.9 $\mathrm{mm}$ ID ; Imamura Co., Tokyo, Japan) were threaded into the left carotid artery cranially and the right brachial artery; then inserted into the amniotic cavity and maternal femoral artery and vein to obtain maternal blood to pre-fill the ECMO circuit. A polyvinyl chloride catheter $(4.7 \mathrm{~mm} \mathrm{OD}$ and $3.5 \mathrm{~mm}$ ID ; Imamura Co.) was also introduced into the maternal trachea by way of an aseptic midline ventral neck incision. Fetal catheters, electrodes and maternal femoral catheters were exposed through an incision in the left flank of the mother.

After surgery and before initiating the experiments, $1 \mathrm{~g}$ flomoxef sodium (Shionogi \& Co., Ltd, Osaka, Japan) was administered to the mother through the femoral vein catheter every $12 \mathrm{~h}$. The animals were allowed to recover for at least $24 \mathrm{~h}$ after surgery. Experiments were performed on the fetuses from 126 to 134 days of gestation.

\section{Extracorporeal membrane oxygenation circuit}

We used a membrane oxygenator (MERA Silox S 0.5 ; Mera, Tokyo, Japan) with a heat exchanger for our ECMO system (550 Bio-console ; Medtronic Bio-medicus Inc., MN, USA). Before the experiments, the entire ECMO circuit was pre-filled with $200 \mathrm{ml}$ of heparinized maternal blood using a centrifugal pump (HPM-15, priming volume $25 \mathrm{ml}$; Nikkiso Ltd, Tokyo, Japan). The blood was warmed to between $38^{\circ} \mathrm{C}$ and $39^{\circ} \mathrm{C}$ with a heat exchanger. Blood flow rates (in $\mathrm{ml} / \mathrm{min}$ ) were determined with an in-line electromagnetic flow sensor (T206 ; Transonic Systems Inc., Ithaca, NY, USA). Heparin was continuously infused into the circuit to prevent coagulation, and the fetal activating clotting time was monitored frequently with a Hemochron model 801 (International Technidyne Co., Edison, NJ, USA). The fetal activating clotting time was maintained at approximately $300 \mathrm{~s}$ to prevent clot formation within the circuit. At the beginning of the experiments, prostaglandin E1 (Mitsubishi Pharma Co., Osaka, Japan) was given to the fetus by intravenous bolus injection (15 micrograms), followed by a bolus injection at the beginning of each ECMO system to maintain the patency of the ductus arteriosus. 


\section{Experimental protocol (Fig. 1)}

The blood in the ECMO circuit was obtained through a 12-Fr Teflon double-lumen catheter inserted into the right fetal atrium. After oxygenation, the blood was returned through a 9-Fr Teflon single-lumen catheter in the fetal carotid artery (V-A ECMO ; blood flow 50-60 ml/min, Fig. 2) or the second lumen of the double-lumen catheter in the right fetal atrium (V-V ECMO; blood flow $50-60 \mathrm{ml} / \mathrm{min}$, Fig. 3) ${ }^{7}$. Oxygen and compressed air were mixed and flowed at $1 \mathrm{l} / \mathrm{min}$ to ventilate the membrane.

After non-hypoxic control (baseline control),

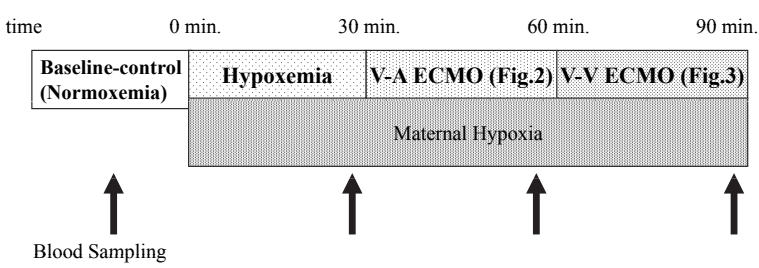

Fig. 1. Experimental protocol. V-A ECMO, right atrium to carotid artery extracorporeal membrane oxygenation ; V-V ECMO, right atrium to the right atrium extracorporeal membrane oxygenation. Arrow sign; blood collection time.

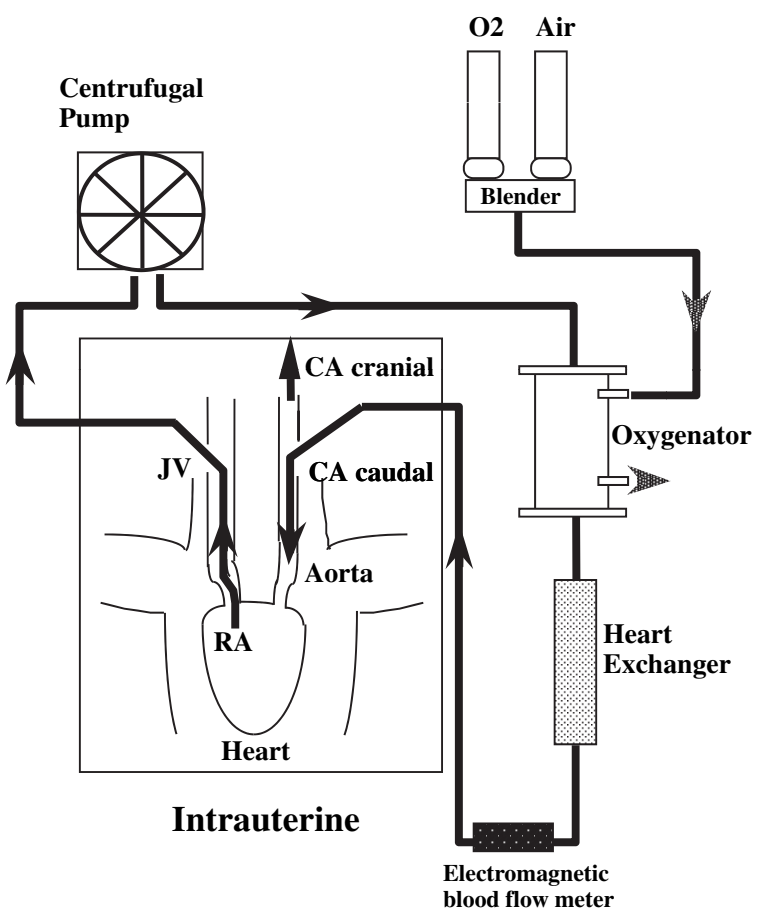

Fig. 2. Right atrium (RA) to carotid artery (CA) extracorporeal membrane oxygenation ( $\mathrm{V}-\mathrm{A}$ ECMO) system for fetal oxygenation support in utero. JV catheter inserted caudally into jugular vein until right atrium was reached. blood samples had been drawn for blood gas and endocrinological analysis, fetal hypoxia was induced by nitrogen infusion at 3.5-5.0 $\mathrm{l} / \mathrm{min}$ into the maternal trachea catheter, which lowered the maternal fraction inspiratory oxygen $(\mathrm{FiO} 2)^{10)}$. We regulated nitrogen flow to maintain fetal arterial oxygen partial pressure (pO2) at approximately $12 \mathrm{mmHg}$. After $30 \mathrm{~min}$ of fetal hypoxia, V-A ECMO was instituted for $30 \mathrm{~min}$ to maintain fetal oxygenation. Subsequently, V-A ECMO was switched to V-V ECMO, and the same blood samples were drawn. After the initiation of each ECMO system, the same dose of maternal nitrogen infusion was used to create the same fetal hypoxic condition. Although the oxygen concentration presented to the membrane may have differed slightly among the fetuses, the same concentration was used during both ECMO routes in each fetus. The ECMO blood flow was maintained at approximately $50-60 \mathrm{ml} / \mathrm{min}$ throughout each experiment. Blood samples were anaerobically and simultaneously drawn from the fetal cranial carotid artery, the fetal brachial artery, and the ECMO circuit. Fetal and maternal blood $\mathrm{pH}$ and gases were measured using a blood gas analyzer (ALB 555 ; Radiometr Co., Copenhagen, Denmark) with the temperature corrected to $38^{\circ} \mathrm{C}$. Fetal arterial

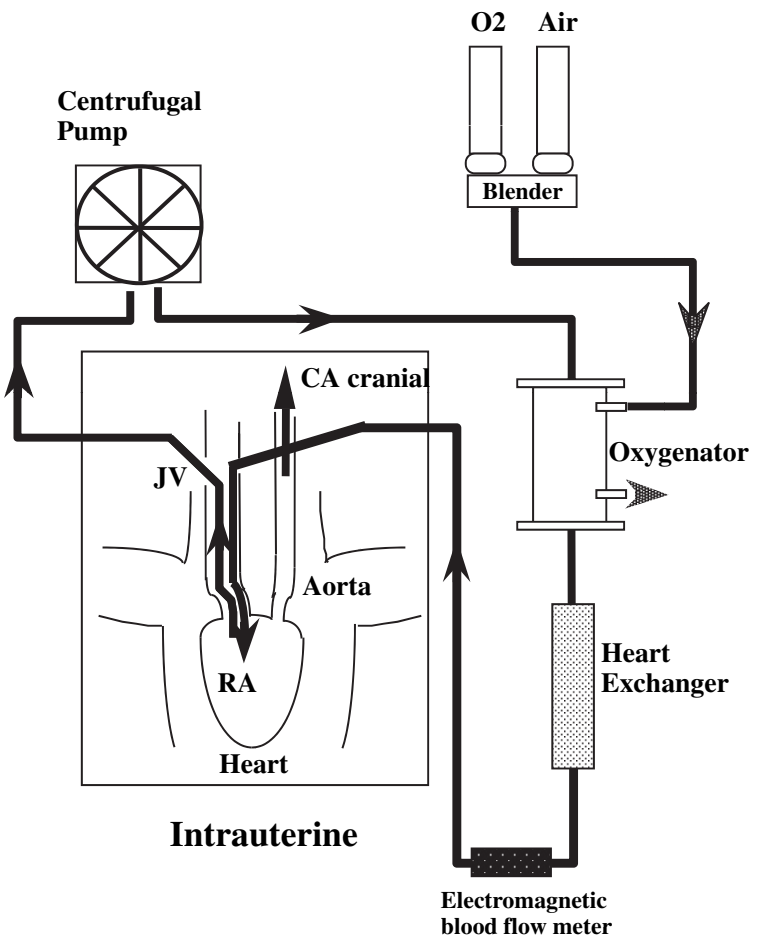

Fig. 3. Right atrium (RA) to RA extracorporeal membrane oxygenation (V-V ECMO) system for fetal oxygenation support in utero. JV catheter inserted caudally into juglar vein until right atrium was reached. 
blood pressure corrected for intra-amniotic pressure and FHR were analyzed every minute for $5 \mathrm{~min}$ prior to each blood sampling. The plasma ANP concentration was measured using modified radioimmunoassay ${ }^{11)}$. The sensitivity of the assay of ANP was $5 \mathrm{pg} / \mathrm{ml}$. The inter- and intra-assay coefficients of variation in ANP were $4.7 \%$ and $6.4 \%$. Concentrations of epinephrine and norepinephrine in the fetal plasma were measured after extraction with high performance liquid chromatography by electrochemical detection ${ }^{12)}$. Fig. 1 gives an overview of the experimental procedure.

\section{Statistical analysis}

All data are presented as means \pm standard error (SE.). Statistical analysis was performed by Freedman-test. For fetal blood gas analysis, fetal blood pressure and fetal heart rate, when a significant $P$ value was obtained, Wilcoxon signed rank test was used to compare the baseline control with hypoxemia and to compare V-A ECMO with V-V ECMO. Furthermore, after having performed similar statistics in ANP, epinephrine and norepinephrine, we compared hypoxemia with V-V ECMO and V-A ECMO using Bonferroni correction. All statistical analyses were performed using SPSS software (version 17.0, SPSS Co. Japan). A value of $p<0.05$ was considered significant.

\section{RESULTS}

\section{Fetal arterial blood gases and $p H$}

Fetal cranial carotid arterial $\mathrm{pO} 2$ was reduced to $12.7 \pm 0.8 \mathrm{mmHg}$ from $19.4 \pm 3.1 \mathrm{mmHg}$ by reducing the $\mathrm{FiO} 2$ of the mother. After maintaining $\mathrm{V}-\mathrm{A}$
ECMO or V-V ECMO for $30 \mathrm{~min}, \mathrm{pO} 2$ in the fetal cranial carotid artery recovered significantly from the hypoxic level to $20.5 \pm 2.2 \mathrm{mmHg}(p<0.05)$ and $21.1 \pm 2.7 \mathrm{mmHg}(\phi<0.05)$, respectively. Carbon dioxide partial pressure (pCO2) in the fetal cranial carotid artery was not altered significantly throughout the experiments. Fetal cranial carotid arterial $\mathrm{pH}$ did not change significantly during fetal hypoxemia. After instituting V-A ECMO or V-V ECMO, fetal metabolic acidosis increased significantly from $7.23 \pm 0.02$ to $7.12 \pm 0.05(p<0.05)$ or $7.09 \pm 0.05$ $(\phi<0.05)$, respectively. (Table 1$)$

Blood gas data from the fetal brachial artery showed similar findings to those from the fetal cranial carotid artery. Fetal brachial arterial $\mathrm{pH}$ status during fetal hypoxemia $(7.23 \pm 0.02)$ advanced significantly to acidosis during $\mathrm{V}-\mathrm{V}$ ECMO $(7.08 \pm 0.05$; $p<0.05)$, but not V-A ECMO $(7.20 \pm 0.03)$. Fetal brachial arterial pO2 was reduced from 19.6 \pm 1.5 $\mathrm{mmHg}$ to $13.4 \pm 0.8 \mathrm{mmHg}$ by reducing maternal FiO2. After maintaining V-A ECMO or $\mathrm{V}-\mathrm{V}$ ECMO for $30 \mathrm{~min}$, fetal brachial arterial pO2 values recovered from the hypoxic level to $19.4 \pm 2.1$ $(\phi<0.05)$ or $17.8 \pm 1.6 \mathrm{mmHg}(\phi<0.05)$, respectively. Fetal brachial arterial $\mathrm{pCO} 2$ was reduced to $38.9 \pm 4.2 \mathrm{mmHg}$ from $49.7 \pm 3.1 \mathrm{mmHg}$ during V-A ECMO but not V-V ECMO which was $47.4 \pm 3.0$ mmHg. (Table 1)

\section{Fetal heart rate and blood pressure}

FHR decreased from $179 \pm 7 \mathrm{bpm}$ in the baseline control to $155 \pm 11 \mathrm{bpm}$ during hypoxemia. After V-A ECMO, FHR increased to $202 \pm 19$ bpm compared to the hypoxemia state. Then, FHR slightly decreased after V-V ECMO to $175 \pm 6.1 \mathrm{bpm}$. As a result, during this experiment, FHR did not show

Table 1. Change in fetal blood $\mathrm{pH}$ and gases

\begin{tabular}{lclll}
\hline & Baseline Control & Hypoxemia & V-A ECMO & V-V ECMO \\
\hline Cranial carotid artery & & & \\
pH & $7.25 \pm 0.01$ & $7.23 \pm 0.02$ & $7.12 \pm 0.05^{\mathrm{a}}$ & $7.09 \pm 0.05^{\mathrm{b}}$ \\
pO2 & $19.4 \pm 3.1$ & $12.7 \pm 0.8$ & $20.5 \pm 2.2^{\mathrm{a}}$ & $21.1 \pm 2.7^{\mathrm{b}}$ \\
pCO2 & $37.7 \pm 3.1$ & $34.2 \pm 4.3$ & $37.0 \pm 3.3$ & $39.5 \pm 4.0$ \\
& & & & \\
Brachial artery & & & & \\
pH & $7.25 \pm 0.01$ & $7.21 \pm 0.02$ & $7.20 \pm 0.03$ & $7.08 \pm 0.05^{\mathrm{b}}$ \\
pO2 & $19.6 \pm 1.5$ & $13.4 \pm 0.8$ & $19.4 \pm 2.1^{\mathrm{a}}$ & $17.8 \pm 1.6^{\mathrm{b}}$ \\
pCO2 & $49.7 \pm 3.1$ & $45.9 \pm 3.0$ & $38.9 \pm 4.2$ & $47.4 \pm 3.0$ \\
\hline
\end{tabular}

All data are expressed as mean \pm SE.

a : $p<0.05$; Hypoxemia vs. V-A ECMO

b : $p<0.05$; Hypoxemia vs. V-V ECMO 
a significant change. Fetal systolic (control ; 66 \pm 7 $\mathrm{mmHg}$ ) and diastolic (control ; $40 \pm 5 \mathrm{mmHg}$ ) blood pressure did not change significantly either during these experiments. However, fetal blood pressure increased just after start of $\mathrm{V}-\mathrm{A} \mathrm{ECMO}$, and tended to increase during this ECMO.

\section{Fetal blood ANP concentration}

Fig. 4 shows fetal blood ANP concentrations in baseline control, hypoxic condition, V-A ECMO, and $\mathrm{V}-\mathrm{V}$ ECMO. Fetal serum ANP concentrations increased from $97 \pm 117 \mathrm{pg} / \mathrm{mL}$ at baseline to $137 \pm 59 \mathrm{pg} / \mathrm{mL}$ after hypoxic stimulation with no significance. They increased to $306 \pm 96 \mathrm{pg} / \mathrm{mL}$ after instituting V-A ECMO and significantly decreased to $138 \pm 36 \mathrm{pg} / \mathrm{mL}$ after instituting V-VECMO compared to that of after instituting $\mathrm{V}-\mathrm{A}$ $\operatorname{ECMO}(\phi<0.05)$.

\section{Fetal blood epinephrine/norepinephrine concentrations}

Figs. 5 and 6 show fetal blood epinephrine/norepinephrine concentrations in baseline-control, hypoxic condition, V-A ECMO and V-V ECMO.

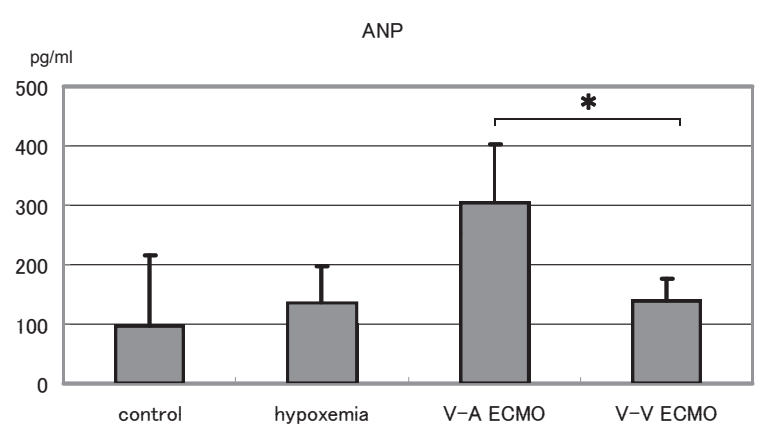

Fig. 4. The plasma ANP concentration from fetal lambs caused hypoxemia after instituting V-A ECOM or V-V ECMO system $(n=6)$. Data are presented as the mean \pm SE. $\quad p<0.05$

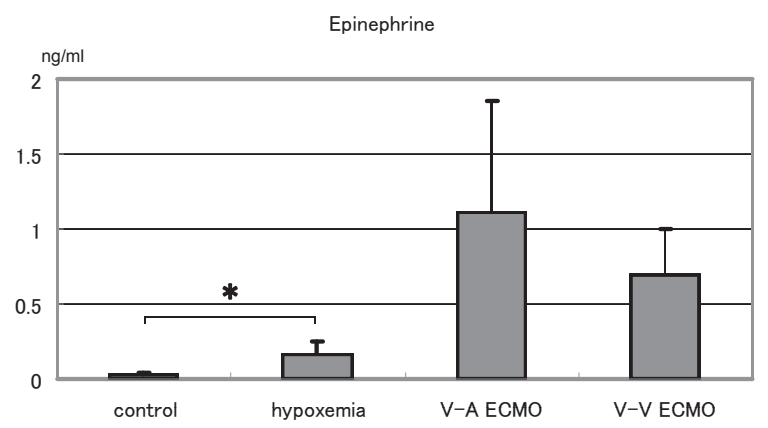

Fig. 5. The plasma epinephrine concentration from fetal lambs caused hypoxemia after instituting V-A ECOM or $\mathrm{V}-\mathrm{V}$ ECMO system $(n=6)$. Data are presented as mean \pm SE. $\quad p<0.05$.
Fetal serum epinephrine concentrations significantly increased from $0.03 \pm 0.01 \mathrm{ng} / \mathrm{mL}$ at baseline to $0.17 \pm 0.08 \mathrm{ng} / \mathrm{mL}$ after hypoxic stimulation $(p<0.05)$. They further increased to $1.11 \pm 0.74 \mathrm{ng} /$ $\mathrm{mL}$ after instituting $\mathrm{V}-\mathrm{A}$ ECMO. They decreased to $0.70 \pm 0.30 \mathrm{ng} / \mathrm{mL}$ after instituting $\mathrm{V}-\mathrm{V}$ ECMO compared to V-A ECMO without significant differences in concentrations between V-V ECMO and V-A ECMO.

Fetal blood norepinephrine concentrations significantly increased from $0.52 \pm 0.12 \mathrm{ng} / \mathrm{mL}$ at baseline to $1.23 \pm 0.19 \mathrm{ng} / \mathrm{mL}$ after hypoxic stimulation $(p<0.05)$. They further increased to $2.99 \pm 1.01 \mathrm{ng} /$ $\mathrm{mL}$ after instituting V-A ECMO. They decreased to $2.66 \pm 0.48 \mathrm{ng} / \mathrm{mL}$ after instituting V-V ECMO compared to V-A ECMO, without significant differences in concentrations between V-V ECMO and V-A ECMO.

\section{DISCUSSION}

In recent years, ECMO has rapidly been developed for the management of respiratory/circulation assistance in neonatal medicine. We examined the impact of V-A ECMO or V-V ECMO on ANP, endocrinal factors of epinephrine and norepinephrine, fetal arterial blood gas, fetal heart rate, and fetal blood pressure in fetal-placental circulation. There has been no experiment on the effects of instituting V-A ECMO or V-V ECMO on fetal ANP, epinephrine, and norepinephrine.

Blood is obtained from the right fetal atrium and returned to the caudal carotid artery in V-A ECMO, while a catheter is placed into the right atrium through which blood is obtained and returned in $\mathrm{V}-\mathrm{V}$ ECMO. V-A ECMO and V-V ECMO has a different site into which blood is returned, resulting in differences in their characteristics. Murata and

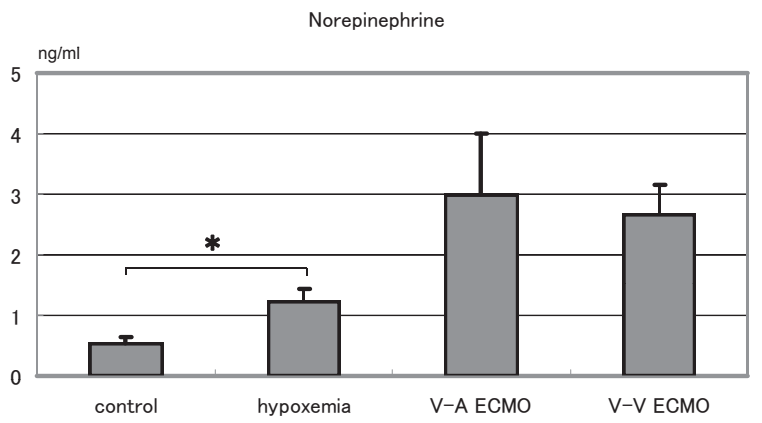

Fig. 6. The plasma norepinephrine concentration from fetal lambs caused hypoxemia after instituting V-A ECOM or $\mathrm{V}-\mathrm{V}$ ECMO system $(n=6)$. Data are presented as mean \pm SE. $\quad p<0.05$. 
coworkers reported the usefulness of fetal oxygenation by V-A ECMO when the mothers were kept under hypoxic conditions in the presence of fetalplacental circulation after preparing the chronic fetal sheep experiment model ${ }^{3)}$. In V-A ECMO, blood is returned to the carotid artery skipping the heart, which might therefore be suitable as a circulating system that assists cardiac function in cases with lowered cardiac function. Nakamura and cowork$\mathrm{ers}^{13)}$ reported in a newborn dog study that oxygenation of the coronary artery is maintained because oxygenated blood is sent to the carotid artery and then reaches the left atrium via the pulmonary artery and then the pulmonary vein by a left-toright shunt via the ductus arteriosus. Accordingly, in fetuses with right-to-left shunts via the ductus arteriosus, blood oxygenated by $\mathrm{V}-\mathrm{A}$ ECMO and sent into the carotid artery has difficulty reaching the left atrium, and thus blood oxygen saturation in the left atrium was low during $\mathrm{V}-\mathrm{A} \mathrm{ECMO}^{4}$. $\mathrm{V}-\mathrm{V}$ ECMO, on the other hand, returns blood into the right atrium, so fetal circulation is thus more physiologic. The blood flow rate into the heart is greater with better oxygen supply when returning oxygenated blood into the right atrium via the umbilical artery than when returning blood into the carotid artery ${ }^{4,14)}$. Although returning blood into the umbilical vein is difficult inside the uterus, returning blood into the right atrium seems to obtain a similar effect to that obtained by returning blood into the umbilical vein. In the present experiment, $\mathrm{V}-\mathrm{V}$ ECMO was as favorable as V-A ECMO in oxygenation and as effective in improving fetal hypoxemia. However, V-V ECMO was instituted subsequently to instituting $\mathrm{V}-\mathrm{A}$ ECMO, and it took 60 minutes to institute all ECMOs, resulting in advanced acidosis during V-V ECMO. In the present study, the blood flow rate in the ECMO circuit was $50 \mathrm{~mL} / \mathrm{min}$ (approximately $25 \mathrm{~mL} / \mathrm{kg} / \mathrm{min}$ ), at which advanced acidosis could not possibly be controlled due to insufficient circulating blood volume. Development of a catheter ensuring higher flow rates is necessary to prevent advanced acidosis in the hypoxic condition. Since oxygen constricts the blood vessels ${ }^{15)}$, an influx of highly oxygenated blood may have induced contractions of the peripheral vessels, and consideration of optimum oxygen concentration in ECMO circuit also seemed necessary.

Although neither change showed significance, fetal heart rate increased during the ECMO and fetal blood pressure had risen just after the start of V-A ECMO. Epinephrine and norepinephrine have major roles in the stress reaction to elevate heart rate and/or blood pressure. Hypoxic stress on a fetus increases epinephrine and norepinephrine levels. In the present experiment, fetal serum epinephrine and norepinephrine concentrations increased in association with hypoxic stimulation. Since the results of epinephrine and norepinephrine measured were high at the same time, ECMO was considered as stress for fetuses. However after instituting V-V ECMO, both concentrations showed no significant differences from those after instituting V-A ECMO. This result supported that there were different influences on fetuses between V-A ECMO and V-V ECMO. V-V ECMO was less hypoxic and a less traumatic system for fetuses, because epinephrine and norepinephrine concentrations did not show significant increases after instituting $\mathrm{V}-\mathrm{V}$ ECMO compared to V-A ECMO.

ANP is a hormone that consists of 28 amino acids. It is now well established that ANP plays a major role in cardiovascular regulation through their natriuretic, diuretic, and vasorelaxant activities, as well as the end-organ activities that suppress cardiac hypertrophy and fibrosis and cardiomyocyte apoptosis $^{16)}$. In fetuses, levels of ANP are higher than in adults ${ }^{17}$. Factors stimulating ANP secretion in fetuses include the volume burden on circulation, high osmotic pressure, hypoxic stimuli, and vasoconstricting effectors ${ }^{18)}$. In animal experiments, increases in ANP found in association with administration of normal saline in fetal sheep ${ }^{14,19,20)}$ and ANP secretion in association with the volume burden on fetal circulating blood volume ${ }^{14,19,20)}$ were reported. It was also reported that the $\mathrm{N}$-terminal peptide value of pro-atrial natriuretic peptides (a precursor of ANP) in umbilical arterial blood may increase when abnormal blood pressure is found in the mother or when fetal hypoxemia occurs during delivery, which is thus a sign of placental insufficiency and/or fetal heart failure ${ }^{21)}$. Furthermore, fetal blood ANP concentrations were reported to have continuously high levels under chronic hypoxic stimulation $^{9)}$. Vasoconstricting effectors, such as angiotensin II, phenylephrine, vasopressin, and endothelin, are also known to act as factors affecting ANP stimulation. In the present study, ANP increased after instituting V-A ECMO and then significantly decreased after instituting $\mathrm{V}-\mathrm{V}$ ECMO. Contrary to V-A ECMO that returns blood into the carotid artery skipping the heart, $\mathrm{V}-\mathrm{V}$ ECMO that returns blood into the right atrium was expected to have higher ANP considering the vol- 
ume burden on the atrium. The present results, however, did not support this assumption. In V-A ECMO, ANP was high possibly because of the combination of multiple factors, such as expected insufficient oxygenation of the heart in fetuses with elevated heart rates due to decreases in venous return or without pulmonary circulation due to lack of pulmonary respiration. For surgical invasion in fetuses, V-V ECMO is less invasive than V-A ECMO because the former involves only the jugular vein.

In conclusion, it was suggested that $\mathrm{V}-\mathrm{V}$ ECMO was a less invasive treatment than V-A ECMO for fetal hearts, because ANP, a cardiac distress index ${ }^{222}$, was significantly lower in V-V ECMO than in V-A ECMO. However, it has the drawback of advanced acidosis, therefore the development of better catheters is necessary in future.

\section{REFERENCES}

1. Bartlett RH, Gazzaniga AB, Jefferies MR. Extracorporeal membrane oxygenation (ECMO) cardiopulmonary support in infants. Trans Am Soc Artif Intern Organs, 22 : 80-93, 1976.

2. Schaible T, Hermle D, Loersch F, Demirakca S, Reinshagen K, Varnholt V. A 20-year experience on neonatal extracorporeal membrane oxygenation in a referral center. Intensive Care Med, 36 : 1229-1234, 2010.

3. Murata Y, Ibara S, Quilligan EJ, Oka S, Endo C, Fujimori K, Kamimura T. Effects of extracorporeal membrane oxygenation (ECMO) on fetal lambs. J Matern Fetal Med, 4 : 46-50, 1995.

4. Murata Y, Fujimori K, Quilligan EJ, Nagata N, Ibara S, Hirano T, Kamimura T. Cardiac oxygenation by extracorporeal membrane oxygenation in exteriorized fetal lambs. Am J Obstet Gynecol, 174: 864-870, 1996.

5. Andrews AF, Klein MD, Toomasian JM, Roloff DW, Bratlett RH. Venovenous extracorporeal membrane oxygenation in neonates with respiratory failure. J Pediat Surg, 18 : 339-346, 1983.

6. Zahraa JN, Moler FW, Annich GM, Maxvold NJ, Bartlett RH, Custer JR. Venovenous versus venoarterial extracorporeal life support for pediatric respiratory failure: are there differences in survival and acute complications? Critical Care Medicine, 28 : 521-525, 2000.

7. Fujimori K, Nomura Y, Kato K, Shiroto T, Ishida T, Sato A. The effects of veno-venous extracorporeal membrane oxygenation on hypoxic fetal lambs. The J Mater-Fet Neonat Med, 16 : 119124, 2004.

8. Fujimori K, Endo C, Kin S, Funata Y, Araki T, Sato
A, Murata Y. Endocrinologic and biophysical responses to prolonged (24-hour) hypoxemia in fetal goats. Am J Obstet Gynecol, 171 : 470-477, 1994.

9. Yamada J, Fujimori K, Ishida T, Sanpei M, Honda S, Sato A. Plasma endothelin-1 and atrial natriuretic peptide levels during prolonged (24-h) non-acidemic hypoxemia in fetal goats. J Maternal Fetal Med, 10 : 409-413, 2001.

10. Gleed RD, Poore ER, Figueroa JP, Nathanielsz PW. Modification of maternal and fetal oxygenation with the use of tracheal gas infusion. Am J Obstet Gynecol, 155 : 429-435, 1986.

11. Takei Y, Ando K, Kawakami M. Atrial natriuretic peptide in eel plasma, heart and brain characterized by homologous radioimmunoassay. J Endocrinol, 135 : 325-331, 1992.

12. Maruta K, Fujita K, Ito, S. Liquid Chromatography of Plasma Catecholamine with Electrochemical Detection, after Treatment with Boric Acid Gel. Clin Chem, 30 : 1271-1273, 1984.

13. Nakamura T, Takata M, Arai M, Nakagawa S, Miyasaka K. The effect of left-to-right shunting on coronary oxygenation during extracorporeal membrane oxygenation. J Pediatr Surg, 34 : 981985, 1999.

14. Miner LK, Cheung CY, Brace RA. Autonomic modulation of fetal atrial natriuretic factor and urine flow response to vascular volume expansion. Am J Obstet Gynecol, 159 : 1341-1346, 1988.

15. Wheeler EC, Brenner ZR. Peripheral vascular anatomy, physiology, and pathophysiology. AACN Clin Issues, 6 : 505-514, 1995.

16. Misono KS, Philo JS, Arakawa T, Ogata CM, Qiu Y, Ogawa H, Young HS. Structure, signaling mechanism and regulation of the natriuretic peptide receptor guanylate cyclase. FEBS J, 278 : 18181829, 2011.

17. Das BB, Raj S, Solinger R. Natriuretic peptides in cardiovascular diseases of fetus, infants and children. Cardiovasc Hematol Agents Med Chem, 7 : 43-51, 2009.

18. Vicky C, Leigh E. Natriuretic Peptidesduring Development of the Fetal Heart and Circulation. Endocrinology, 144 : 2191-2194, 2003.

19. Brace RA. Fetal blood volume, urine flow, swallowing, and amniotic volume responses to longterm infusion of saline. Am J Obstet Gynecol, 161 : 1049-1054, 1989.

20. Ross MG, Ervin MG, Lam RW, Leake RD, Fisher DA. Fetal atrial natriuretic factor and arginine vasopressin responses to hyperosmolality and hypervolemia. Pediatr Res, 24 : 318-321, 1988.

21. Kaarin M, Olli V, Pentti J, Juha R. Umbilical artery $\mathrm{N}$-terminal peptide of proatrial natriuretic 
peptide in hypertensive pregnancies and fetal acidemia during labor. Obstet Gynecol, 97 : 23-28, 2001.

22. Ghosh N, Haddad H. Atrial natriuretic peptides in heart failure: pathophysiological significance, diagnostic and prognostic value. Can J Physiol Pharmacol, 89 : 587-591, 2011. 